\title{
Mode of Action of Chlorothiazide in the Reduction of Blood Pressure in Hypertension*
}

\author{
James Conway, m.D., Ph.D. and Philip Lauwers, m.D.
}

Ann Arbor, Michigan

$\mathrm{T}$ HERE Is considerable circumstantial evidence that hypertension is associated with abnormalities of water and electrolyte metabolism. In man this evidence rests mainly upon the fact that a low sodium diet will frequently reduce blood pressure ${ }^{1,2}$ and that salt-retaining hormones will produce hypertension. ${ }^{3}$ A drug which lowers blood pressure by producing a pronounced and continued diuretic effect upon the kidney must, therefore, be of considerable interest. Before such a drug could be regarded as affecting the disease process, however, it would be necessary to show that it acts by reducing peripheral resistance.

At first sight, chlorothiazide did not appear to fit this role since its hypotensive action was shown by Freis ${ }^{4}$ and Dustan ${ }^{5}$ to result from a loss of plasma volume and thereby a reduction in cardiac output. We made measurements similar to these but under different circumstances. Our studies consisted in measurement of cardiac outputs of patients who had been taking chlorothiazide, $1 \mathrm{gm}$. per day, continuously for at least 1 month; whereas both Freis and Dustan determined their effects of chlorothiazide after periods of less than 2 weeks.

Cardiac Output: In fifteen of nineteen patients in our series, the cardiac output was either unchanged or increased after chlorothiazide therapy. Only four patients showed a decline in cardiac output. The mean control cardiac index for this group prior to treatment was $3.7 \mathrm{~L}$. per minute. After treatment it was 4.1 L. per minute. Since blood pressure was reduced at this time, the calculated peripheral resistance was also reduced by a mean of 23.6 per cent ${ }^{6}$ (Fig. 1).

Plasma Volume and Peripheral Resistance: Since cardiac output is extremely variable even with every effort to standardize laboratory conditions, we placed considerable importance upon plasma volume determinations made under similar circumstances of treatment. Here again, we were unable to demonstrate a physiologic difference. In ten subjects we noted a mean reduction in plasma volume on only $90 \mathrm{ml} .^{6}$ To satisfy ourselves that these results represented a true difference between the acute and chronic stages of treatment, the effects of plasma volume and cardiac output of short periods of chlorothiazide therapy were studied in seven patients. Plasma volume determinations in four patients showed a mean reduction of $401 \mathrm{ml}$. and cardiac index measurement in four patients showed a mean reduction of $1 \mathrm{~L}$. per minute. In this period, the fall in output was proportionately greater than the 'change in blood pressure; consequently, total peripheral resistance increased by a mean of 14.6 per cent (Fig. 2 ).

It appeared, therefore, that there was a change in the mechanism between the acute and chronic stages of treatment with chlorothiazide. The nature of this change is unknown but it is gratifying to see that the early unphysiologic effect of the drug is replaced after a few weeks of therapy by one which produces reduction of peripheral resistance. To suggest that this mechanism reverses the hypertensive process would be premature, but these findings suggest that chlorothiazide is worthy of more intensive study.

Sodium Depletion and Fall in Body Water: While the initial attention was thrown on the sodium-losing ability of chlorothiazide, it has not been shown that sodium depletion is the essential requirement for the hypotensive effect. Hollander et al. ${ }^{7}$ demonstrated that the exchangeable sodium level can be replenished by the administration of $9 \alpha$ fluorohydrocortisone

* From the Hypertension Unit, Department of Internal Medicine, University of Michigan Medical Center, Ann Arbor, Michigan. 


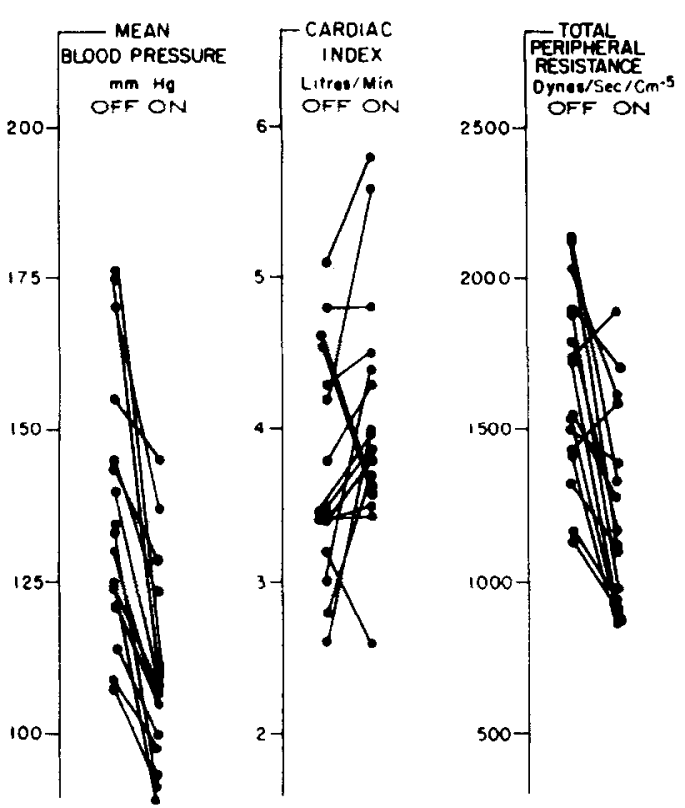

Fig. 1. Effect of long term therapy (more than 4 weeks) with chlorothiazide on blood pressure, cardiac output and peripheral resistance. From: Conway, J. and Lauwers, P. Circulation, 21:21, $1960 .^{6}$

without return of the blood pressure to its pretreatment level. Similarly, a consistent change in the exchangeable sodium after long term therapy with chlorothiazide could not be demonstrated in seven patients studied by us, there being an increase in the value in three patients and a small fall in four. ${ }^{8}$ Others, likewise, have been unable to show a fall in the cxchangeable potassium level. ${ }^{9}$ After long term chlorothiazide therapy the only consistent change that we have been able to determine is a fall in total body water. Since we and others ${ }^{10}$ were unable to show a fall in extracellular fluid volume, we must conclude that this change in total body water represents a loss of intracellular water. In seven patients studied by us, the mean reduction was $1.9 \mathrm{~L}$. This corresponded with a fall in body weight of $1.4 \mathrm{~kg}$.

It remains to be shown whether this change is the one responsible for the fall in blood pressure, but if chlorothiazide is affecting the hypotensive process, it would seem to us that the focus of attention should be on the distribution of body water in hypertension rather than upon sodium. To be sure, these two parameters are closely linked and, like Siamese twins, special tricks will have to be devised to separate them.

Should loss of body water prove to be the essential change responsible for fall in blood pressure produced by chlorothiazide, the problem will remain to elucidate the mechanism by which the peripheral resistance is reduced. The effect on the blood vessels may be upon the contractility of smooth muscle, upon the structure of whole blood vessels as suggested by Tobian ${ }^{11}$ or possibly by an external effect reducing tissue pressure which is exerted on the vascular tree throughout its length. These alternatives are under active investigation at the present time.
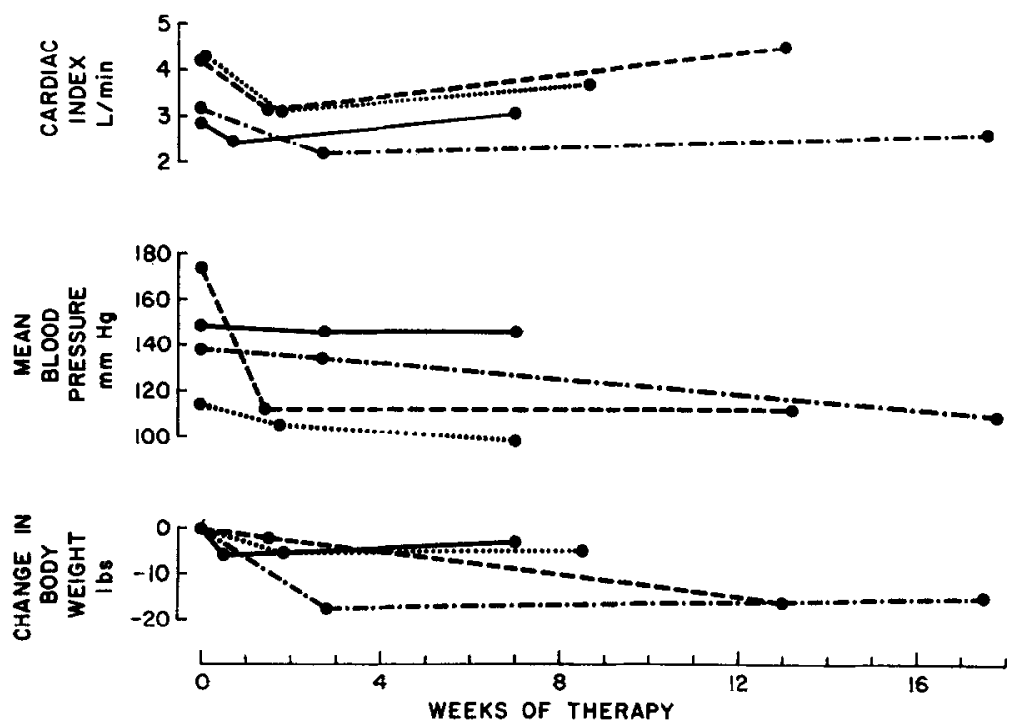

FIG. 2. Changes in cardiac output, blood pressure and body weight with initiation and maintenance of treatment with chlorothiazide. 


\section{Summary}

The possibility that chlorothiazide affects the hypertensive process is a very real one since the effect on the blood pressure of long term treatment is to reduce peripheral resistance.

The means by which this is achieved is unknown. It cannot be shown to be due to loss of sodium since the level of cxchangeable sodium returns to normal on long term treatment. The only change we have been able to observe is a fall in total body water which is believed to be due to a loss of cellular water.

\section{REFERENGES}

1. Allen, F. M. Arterial hypertension. J. A. M. A., $74: 652,1920$.

2. KEMPNER, W. Treatment of kidney disease and hypertensive vascular disease with rice diet. North Carolina M. J., 5: 125, 1944.

3. Conn, J. W. Primary aldosteronism, a new clinical syndrome. J. Lab. \& Clin. Med., 45: 3, 1955.

4. Freis, E. D., W ANko, A., Wilson, I. M. and ParRISH, A. E. Chlorothiazide in hypertensive and normotensive patients. Ann. New York Acad. Sc., $71: 450,1958$.

5. Dustan, H. P., Gumming, G. R., Corcoran, A. C. and PAGE, I, H, A mechanism of chlorothiazideenhanced effectiveness of antihypertensive ganglioplegic drugs. Circulation, 19: 360, 1959.

6. Conway, J. and Lauwers, P. The hemodynamic and hypotensive effects of long-term therapy with chlorothiazide. Circulation, 21:21, 1960.

7. Hollandfr, W., Chorantan, A. V. and Wilkins, R. W. Relationship between diuretic and antihypertensive effects of chlorothiazide and mercurial diuretics. Circulation, 19: 827, 1959.

8. Lauwers, P. and Conway, J. Effect of long-term treatment with chlorothiazide on body fluids, serum electrolytes and exchangeable sodium in hypertensive patients. J. Lab. \& Clin. Med., 56: 401, 1960.

9. Talso, F. J. and Carballo, A. J. Effects of benzothiadiazines on serum and total body electrolytes. Ann. New York Acad. Sc., 88: 822, 1960.

10. Cottier, P. Die Wirkung längerdauern der Chlorothiazidebehandlung auf die Nierenfunktion bei essentieller Hypertonie. Therap. Umschau Med. Bibliographic., 16: 1, 1959.

11. Tobian, L. The electrolytes of arterial wall in experimental renal hypertension. Circulation Res., $4: 671,1956$. 